\title{
The tobacco reliquary
}

$\mathrm{O}$ n Jan. 11, 1964, at a packed press conference in Washington, DC, Dr. Luther L. Terry, surgeon general of the United States Public Health Service, released the report, Smoking and Health: Report of the Advisory Committee to the Surgeon General of the Public Health Service. One of the most important documents in the history of medicine, the report was the culmination of a year-long analysis by 10 scientists of the world literature on the effects of tobacco use. The damning conclusion: "Cigarette smoking is causally related to lung cancer in men ... and is a health hazard of sufficient importance to warrant appropriate remedial action." Six months earlier, on June 17, 1963, Canada's Minister of National Health and Welfare, Judy LaMarsh, had similarly declared in the House of Commons, "There is scientific evidence that cigarette smoking is a contributory cause of lung cancer and that it may also be associated with chronic bronchitis and coronary heart disease."

Surgeon General Terry's indictment of cigarettes in 1964 should have marked the beginning of the end of the Marlboro Man. Yet, far from riding off into the sunset, the tobacco industry is still riding high in the saddle.

Right up until the 2000s, cigarette manufacturers publicly disputed the evidence about the harmfulness of smoking

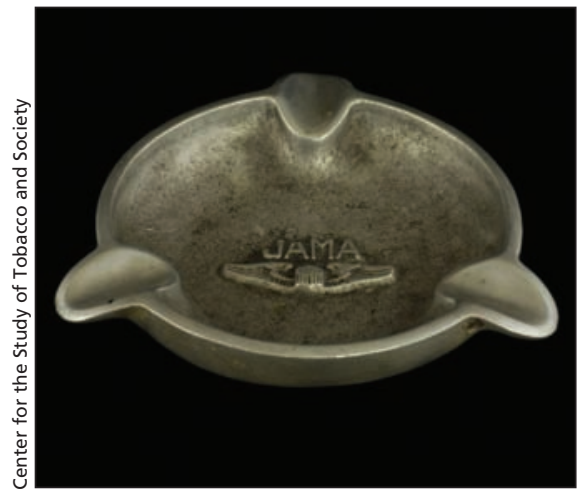

A JAMA ashtray, circa 1955-1960.

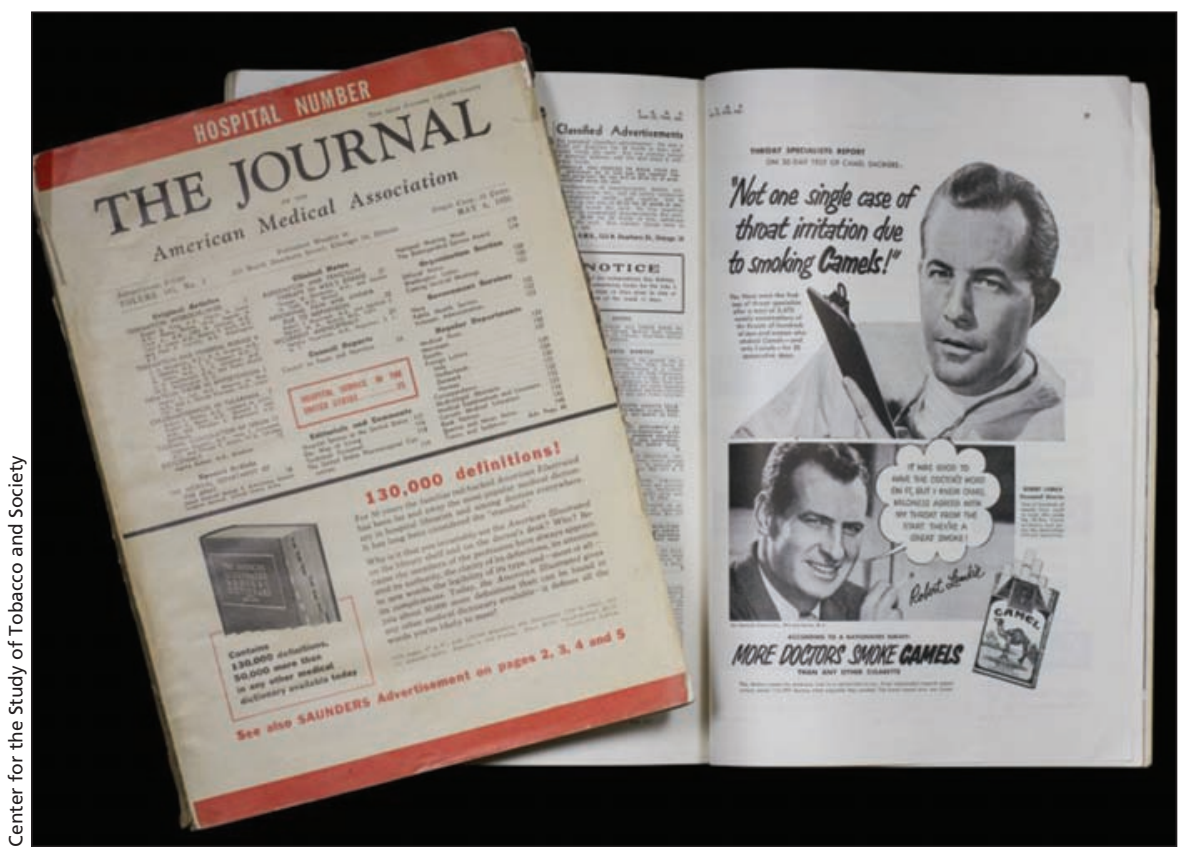

This Camel cigarette advertisement ran in the Journal of the American Medical Association, which accepted cigarette advertising from 1933 to 1954.

and sought to allay consumer anxiety by implying that new filtered, low-tar and "light" brands were not harmful. This corporate-level denial is ongoing in the United States and Canada, as evidenced by testimony in individual and classaction litigation. The result: 50 years after the surgeon general's landmark report, the health and economic toll of smoking remains devastating. Thirty percent of deaths from cancer in the US

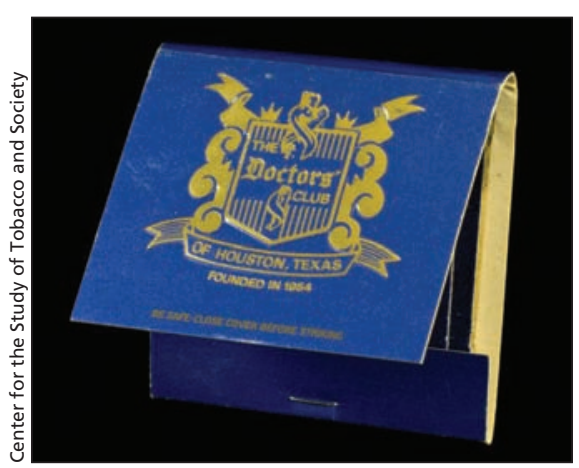

A Doctors' Club matchbook from Houston, Texas, circa 1990.

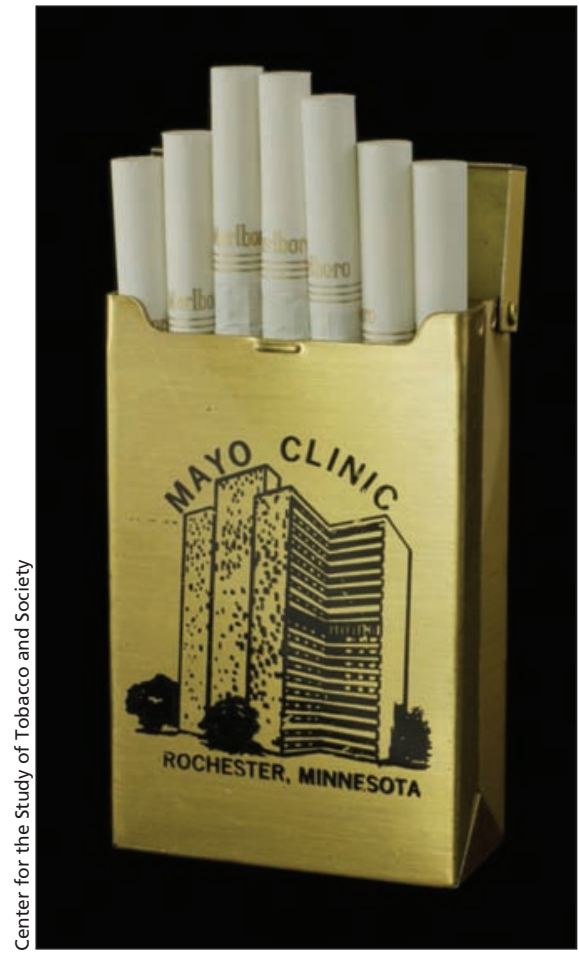

A Mayo Clinic cigarette case, circa 1960. 


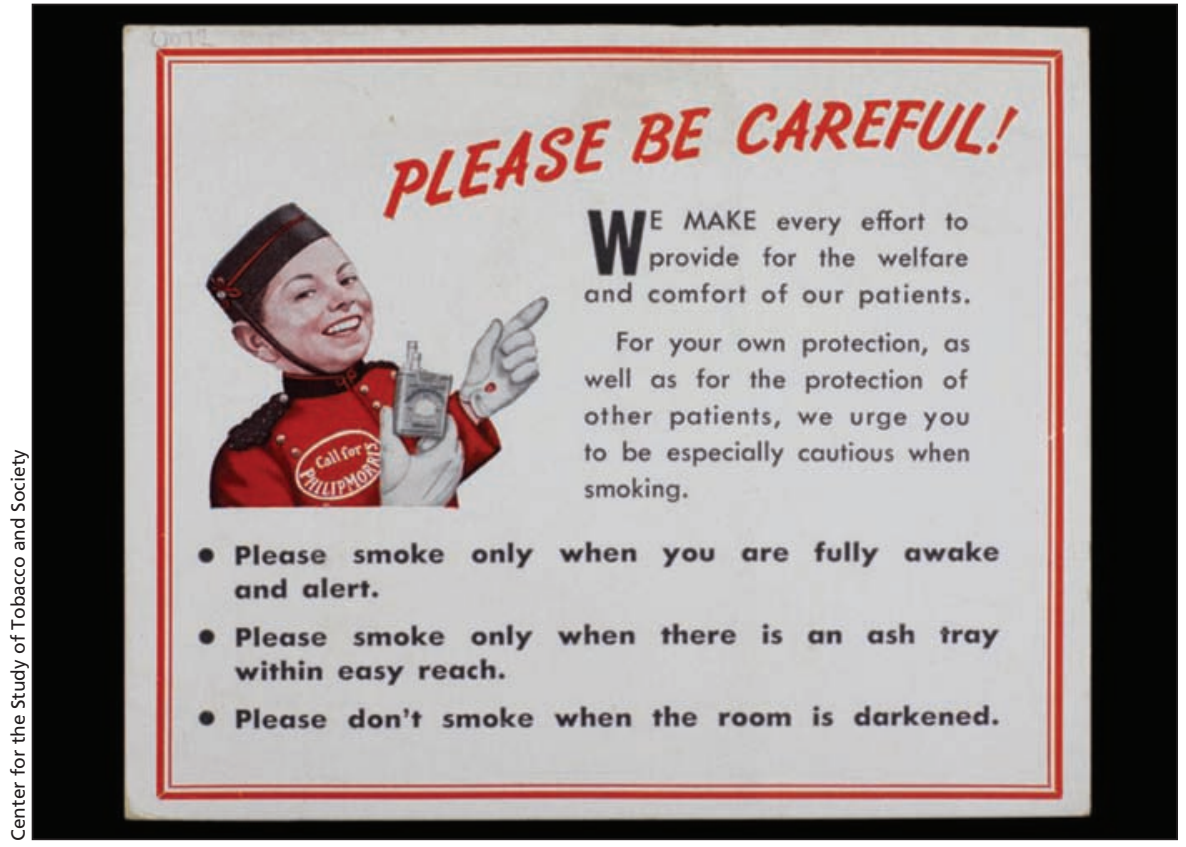

A Philip Morris hospital bedside placard urging carefulness in smoking, circa 1940-1945.

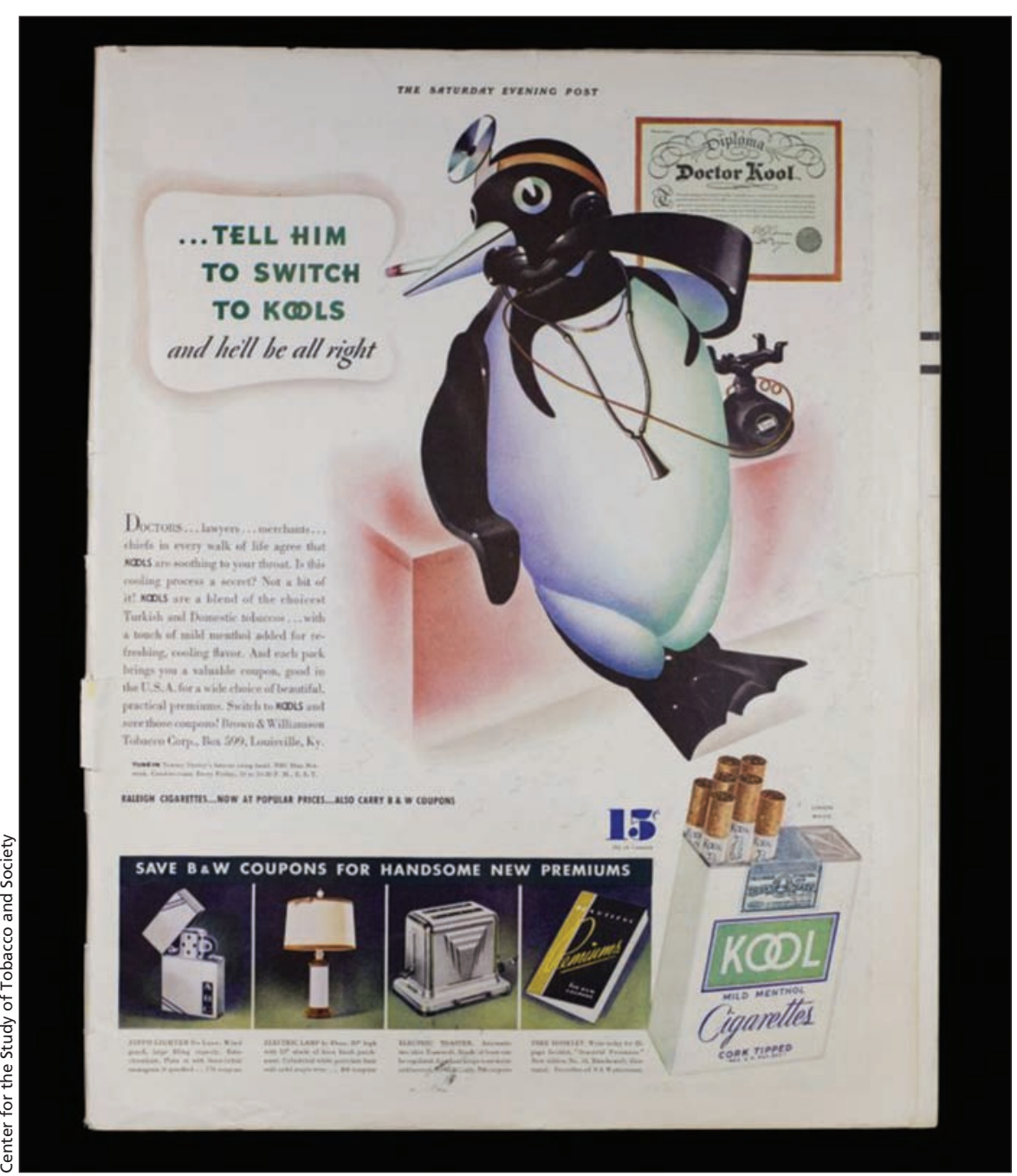

This Brown and Williamson Tobacco Corporation's Kool cigarette advertisement, featuring "Dr. Kool," ran in The Saturday Evening Post, Oct. 23, 1937. are attributable to cigarette smoking. ${ }^{1}$ Although the percentage of American and Canadian adults who smoke cigarettes has declined from about $40 \%$ in 1964 to $18 \%^{2}$ and $16 \%^{3}$ respectively, the number of smokers is not much less than in 1964 - and the cohort may well be younger than ever.

To commemorate the 50th anniversary of this report, I curated an exhibition: The Surgeon General vs. The Marlboro Man: Who Really Won? Through more than 130 artifacts, including cigarette ads in the Journal of the American Medical Association, a cigarette filter made of asbestos, packages of candy cigarettes identical to real ones, hospital ashtrays and a Mayo Clinic cigarette case, the exhibition traces both the promotion of smoking and the efforts to end it.

A companion film, Blowing Smoke: The Lost Legacy of the 1964 Surgeon General's Report on Smoking and Health, ${ }^{4}$ argues that efforts to eliminate smoking have become more symbol than substance. It chronicles the fear, foot-dragging and squandering of funds on the part of public health agencies, universities and organized medicine in ending the smoking pandemic.

The 50th anniversary of the Surgeon General's report is not a time for celebration, but for sober reflection on the tens of millions of Americans and Canadians who have died from smoking even long after Dr. Terry's call to end the tobacco pandemic.

Alan Blum MD (ablum@cchs.ua.edu) The University of Alabama Center for the Study of Tobacco and Society, Tuscaloosa, Ala. (http://csts.ua.edu/)

\section{References}

1. Cancer facts and figures 2014. Atlanta: American Cancer Society; 2014. Available: www.cancer.org /acs/groups/content/@research/documents/webcontent/acspc-042151.pdf (accessed 2014 Nov. 11).

2. Adult cigarette smoking in the United States: current estimates. Atlanta: United States Centers for Disease Control and Prevention; 2014. Available: www.cdc.gov/tobacco/data_statistics/fact_sheets /adult_data/cig_smoking (accessed 2014 Nov. 11).

3. Tobacco use in Canada: patterns and trends. 2014 edition. Waterloo (ON): Propel Centre for Population Health Impact; 2014. Available: www.mantrainc.ca /assets/tobaccouseincanada_2014.pdf (accessed 2014 Nov. 11).

4. Blowing Smoke: The Lost Legacy of the Surgeon General's Report [movie]. Dir. Center for the Study of Tobacco and Society, University of Alabama. 2013. Available: https://docs.google.com/file /d/0B1j5VTNHmZZmcFJWLW1wbDF3Mms/edit (accessed 2014 Nov. 11).

CMAJ 2015. DOI:10.1503/cmaj.141231 